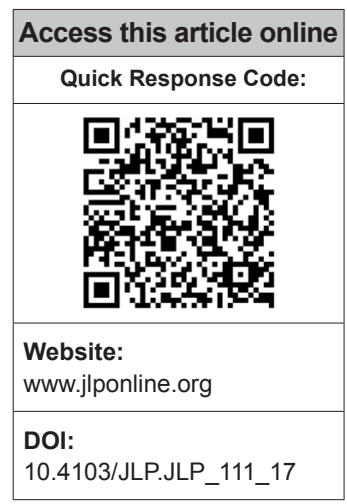

Department of Allied Health Sciences, College of Medicine and Health Sciences, Sultan Qaboos University, ${ }^{1}$ Department of Pathology, Sultan Qaboos

University Hospital, Muscat, Oman

Address for correspondence: Dr. Nasar Alwahaibi, Department of Allied Health Sciences, College of Medicine and Health

Sciences, Sultan Qaboos University, P. O. Box 35 Postal Code 123, Muscat,

Oman.

E-mail: nasar@ squ.edu.om

Submission: 13-06-2017 Accepted: 09-07-2017

\title{
Alternative to xylene as a clearing agent in histopathology
}

\author{
Nasar Alwahaibi, Shaima Aljaradi ${ }^{1}$, Horiyah Alazri ${ }^{1}$
}

\section{Abstract:}

INTRODUCTION: Clearing is an essential step in processing tissue for light microscopy. Xylene is the clearing agent used most commonly worldwide. Xylene is toxic and therefore a threat to personnel working in histopathology laboratories. We evaluated a safer alternative clearing agent for use in the histopathology laboratory.

MATERIALS AND METHODS: We used 230 formalin-fixed, paraffin-embedded tissue blocks from 19 different tissues. Half of the specimens were processed using xylene and half were processed using UltraClear ${ }^{\top M}$. Tissues were evaluated for eight parameters: sectioning, nuclear staining, cytoplasmic staining, overall cell morphology, clarity of staining, uniformity of staining, quality of immunohistochemistry $(\mathrm{IHC})$, and cost.

RESULTS: Both UltraClear ${ }^{\mathrm{TM}}$ and xylene processed sections scored $100 \%$ for IHC. Sections processed using UltraClear ${ }^{\mathrm{TM}}$ were easy to cut $(81.7 \%)$ as were xylene processed sections $(96.5 \%)$. UltraClearTM processed sections showed $67 \%, 60.9 \%, 52.2 \%, 63.5 \%$, and $67 \%$ for nuclear staining, cytoplasmic staining, cell morphology, clarity of staining, and uniformity of staining, respectively. UltraClear ${ }^{\mathrm{TM}}$ is twice as expensive as xylene. We found that tissues processed using UltraClear ${ }^{\mathrm{TM}}$ were easy to cut and worked well for both hematoxylin and eosin and $\mathrm{IHC}$ staining.

CONCLUSION: UltraClearTM is less toxic, less flammable, friendlier to the environment, and easy to handle, but it is two times expensive than xylene. The findings of this study recommend the use of UltraClear ${ }^{\mathrm{TM}}$ solution as a routine clearing agent in histopathology laboratories. However, further studies are required.

Key words:

Clearing agent, histopathology, histoprocessing, UltraClear ${ }^{\mathrm{TM}}$, xylene

\section{Introduction}

C learing is an essential step in histopathology processing for light microscopy. The purpose of clearing is to remove dehydrating agents from tissues and to prepare the tissues for impregnation with the embedding agent. Xylene is the clearing agent used most commonly worldwide. Xylene is a sweet smelling, colorless, aromatic hydrocarbon in liquid or gas form that is found naturally in coal, petroleum, and wood tar. ${ }^{[1]}$ Xylene is preferred by many histologists, because it removes alcohols from tissues rapidly, renders tissues transparent, and facilitates

This is an open access article distributed under the terms of the Creative Commons Attribution-NonCommercial-ShareAlike 3.0 License, which allows others to remix, tweak, and build upon the work non-commercially, as long as the author is credited and the new creations are licensed under the identical terms.

For reprints contact: reprints@medknow.com paraffin infiltration. ${ }^{[2]}$ Xylene also is used as a deparaffinizing solvent, for coverslipping, as a solvent to clean microscopes objectives after use of synthetic immersion oil, and for recycling of used slides. ${ }^{[3]}$ Xylene also is used as a solvent in the rubber, printing, and leather industries. ${ }^{[4]}$

The primary problem with using xylene is its toxicity; long-term exposure is particularly injurious to health. Inhaling xylene vapor causes skin, eye, respiratory tract, and mucous membrane irritation. Xylene also affects the central nervous system and may result in headache, weakness, memory loss, irritability, dizziness, giddiness, loss of coordination and judgment, respiratory depression or difficulty in breathing, loss of

How to cite this article: Alwahaibi N, Aljaradi S, Alazri $\mathrm{H}$. Alternative to xylene as a clearing agent in histopathology. J Lab Physicians 2018;10:189-93. 
appetite, nausea, vomiting, shivering, unconsciousness, coma, and possible death due to respiratory failure. Ingestion of xylene may cause gastrointestinal irritation including abdominal pain, nausea, and vomiting. Xylene also may affect the liver and kidneys. ${ }^{[5]}$

Much has been written about the use of safer, less expensive xylene substitutes. ${ }^{[1,6]}$ Alternative clearing agents include limonene, benzene, toluene, aliphatic and aromatic hydrocarbons, and various types of oils. Some of the alternatives, such as oil solvents, require long processing time. Others such as benzene, limonene, and toluene damage the tissue samples. ${ }^{[1]}$

UltraClear ${ }^{\mathrm{TM}}$ is a colorless, odorless isoparaffin-based liquid that contains C11-12 hydrocarbons that are derived from crude oil fractionation and cracking operations. It is environmentally friendly and exhibits no toxic effects on humans. ${ }^{[7]}$ Physical and chemical properties of UltraClear ${ }^{\mathrm{TM}}$ and xylene are shown in Table 1. We compared the use of UltraClear ${ }^{\mathrm{TM}}$ versus xylene as a clearing agent in histopathology laboratory.

\section{Materials and Methods}

\section{Preparation of tissues}

Nineteen different fresh surgical tissues were obtained and included placenta, for umbilical cord, gall bladder, prostate, appendix, ovary, spleen, products of conception, fallopian tube, breast, thyroid, sebaceous cyst, testis, lipoma, uterus, lung, kidney, omentum, small intestine, and fibroid. Each specimen was cut in half to create two

Table 1: Physical and chemical properties of UltraClear $^{\mathrm{TM}}$ and xylene

\begin{tabular}{lcccc}
\hline Compounds & $\begin{array}{c}\text { Flash } \\
\text { point (C) }\end{array}$ & $\begin{array}{c}\text { Boiling } \\
\text { point (C) }\end{array}$ & $\begin{array}{c}\text { Molecular } \\
\text { weight }\end{array}$ & $\begin{array}{c}\text { Permissible } \\
\text { exposure } \\
\text { limits (ppm) }\end{array}$ \\
\hline $\begin{array}{l}\text { Xylene } \\
\text { UltraClearTM }\end{array}$ & 26.1 & $136-140$ & 106.17 & 100 \\
\hline
\end{tabular}

groups. One group was processed using xylene (Fisher Chemical, Leicestershire, UK) and the other group was processed using UltraClear ${ }^{\mathrm{TM}}$ (Avantor's J. T. Baker, Deventer, the Netherlands). All tissues were fixed in $10 \%$ neutral buffered formalin for $24 \mathrm{~h}$. All tissues were processed using an automated histoprocessor (Spin Tissue Processor Microm STP 120; Thermo Scientific, Walldorf, Germany). All tissues were dehydrated through $70 \%, 95 \%$, and four baths of absolute alcohol. Half of the dehydrated tissues were cleared in three changes of xylene as follows: xylene one and two for $1 \mathrm{~h}$ and each and xylene three for $2 \mathrm{~h}$. The other group was cleared in UltraClear ${ }^{\mathrm{TM}}$. An alternative histoprocessing program was set for particularly fatty tissues [Table 2]. All tissues were embedded in molten paraffin wax using an embedding machine (HistoStar ${ }^{\mathrm{TM}}$; Thermo Fisher Scientific) to prepare blocks. Paraffin blocks were cut at $3 \mu \mathrm{m}$ using a rotatory microtome (Leica RM2135, Nussloch, Germany).

\section{Hematoxylin and eosin staining}

All slides were stained with hematoxylin and eosin $(\mathrm{H} \text { and } \mathrm{E})^{[8]}$ using an autostainer (Tissue-Tek Prisma; Sakura, Nagano, Japan) to evaluate overall tissue morphology. All slides were examined by light microscopy (Olympus, BX 51, Tokyo, Japan). Nuclear and cytoplasmic staining, cell morphology, clarity of staining, and uniformity of staining criteria were used to assess the quality of all sections. ${ }^{[9]}$ It is important to note that UltraClear ${ }^{\mathrm{TM}}$ was not used in all steps of staining.

\section{Immunohistochemistry}

To determine the effects of UltraClear ${ }^{\mathrm{TM}}$ on demonstration of selected antigens in tissue blocks, an equal number of slides from both groups was subjected to immunohistochemistry (IHC). Table 3 shows common antigen markers that we tested for different tissues. The Autostainer Link 48 (DAKO, Glostrup, Denmark) was used to immunostain all slides. Positive and negative controls were run with the test.

Table 2: Histoprocessing schedule for UltraClear ${ }^{\mathrm{TM}}$ on Microm STP 120

\begin{tabular}{|c|c|c|c|c|c|}
\hline Steps & Reagents sequence & Time for general tissues & Time for fatty tissues & Temperature (C) & Vacuum \\
\hline 1 & $10 \%$ neutral-buffered formalin & $10 \mathrm{~min}$ & $10 \mathrm{~min}$ & 25 & No \\
\hline 2 & $70 \%$ alcohol & $1 \mathrm{~h}$ & $30 \mathrm{~min}$ & 25 & No \\
\hline 3 & $95 \%$ alcohol & $1 \mathrm{~h}$ & $1 \mathrm{~h}$ & 25 & No \\
\hline 4 & Absolute alcohol & $1 \mathrm{~h}$ & $1 \mathrm{~h}$ & 25 & No \\
\hline 5 & Absolute alcohol & $1 \mathrm{~h}$ & $1.5 \mathrm{~h}$ & 25 & No \\
\hline 6 & Absolute alcohol & $1.5 \mathrm{~h}$ & $3 \mathrm{~h}$ & 25 & No \\
\hline 7 & Absolute alcohol & $2 \mathrm{~h}$ & $1 \mathrm{~h}$ & 25 & No \\
\hline 8 & UltraClear ${ }^{\mathrm{TM}}$ & $1.5 \mathrm{~h}$ & $2 \mathrm{~h}$ & 25 & No \\
\hline 9 & UltraClear' & $1.5 \mathrm{~h}$ & $3.5 \mathrm{~h}$ & 25 & No \\
\hline 10 & UltraClear ${ }^{\mathrm{TM}}$ & $2.5 \mathrm{~h}$ & $2 \mathrm{~h}$ & 25 & No \\
\hline 11 & Paraffin wax & $2 \mathrm{~h}$ & $2 \mathrm{~h}$ & 60 & Yes \\
\hline 12 & Paraffin wax & $2 \mathrm{~h}$ & $2 \mathrm{~h}$ & 60 & Yes \\
\hline
\end{tabular}


Table 3: Immunohistochemical methods used for different antigens

\begin{tabular}{|c|c|c|c|c|}
\hline Tissues & Markers (Dako, Denmark) & Antigen retrieval (PT Link, Dako, Denmark) & Dilution & Type of antigens \\
\hline Placenta & Vimentin & 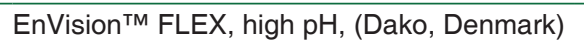 & $1: 50$ & Cytoplasm \\
\hline Prostate chips & P63 & 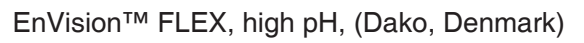 & $1: 50$ & Nuclear \\
\hline Prostate chips & PSA & EnVision ${ }^{\mathrm{TM}}$ FLEX, high pH, (Dako, Denmark) & $1: 50$ & Membrane \\
\hline Appendix & Pan-CK & Proteinase K & $1: 50$ & Membrane \\
\hline Spleen & CD3 & 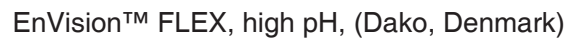 & $1: 50$ & Cytoplasm and Membrane \\
\hline Fallopian tube & WT & 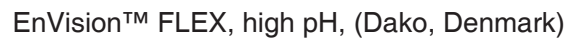 & $1: 50$ & Nuclear \\
\hline Breast & ER & 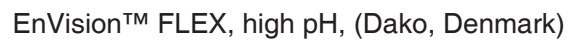 & $1: 20$ & Nuclear \\
\hline Thyroid & Thyroglobulin & EnVision ${ }^{\mathrm{TM}}$ FLEX, high pH, (Dako, Denmark) & $1: 50$ & Cytoplasm \\
\hline Small intestine & CD34 & 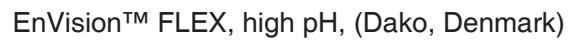 & $1: 50$ & Membrane \\
\hline Gall bladder & SMA & EnVision $^{\mathrm{TM}}$ FLEX, high pH, (Dako, Denmark) & $1: 50$ & Membrane \\
\hline
\end{tabular}

P63 = Protein 63, PSA = Prostate-specific antigen, Pan-CK = Pan cytokeratin, WT = Wilms' tumor, ER = Estrogen receptor, SMA = Smooth muscle actin

Table 4: Modified evaluation criteria and scoring ${ }^{[9]}$

\begin{tabular}{|c|c|c|}
\hline \multirow{2}{*}{$\begin{array}{l}\text { Features } \\
\text { Nuclear staining }\end{array}$} & \multicolumn{2}{|c|}{ Score and criteria } \\
\hline & Acceptable = 1: Round, smooth, and clear nuclear membrane & Unacceptable = 0: Granular, disintegrated, and out of focus \\
\hline Cytoplasmic staining & $\begin{array}{l}\text { Acceptable }=1: \text { Intact cytoplasmic membrane and } \\
\text { transparent cytoplasm }\end{array}$ & $\begin{array}{l}\text { Unacceptable }=0 \text { : Disintegrated cytoplasmic membrane, } \\
\text { granular cytoplasm, and out of focus }\end{array}$ \\
\hline Cell morphology & $\begin{array}{l}\text { Preserved }=1 \text { : Absence of folds, no overlap, and } \\
\text { maintained } \mathrm{N}: \mathrm{C} \text { ratio }\end{array}$ & $\begin{array}{l}\text { Unpreserved }=0 \text { : Overlapping cells, folded, and } \\
\text { disintegrated cells }\end{array}$ \\
\hline Clarity of staining & Present $=1$ : Crispness in staining and transparency & Absent $=0$ : Obliterates the nucleus and cytoplasm \\
\hline Uniformity of staining & Present $=1$ : Uniformly stained throughout the individual cell & $\begin{array}{l}\text { Absent }=0 \text { : Stained in different shades of color in an } \\
\text { individual cell }\end{array}$ \\
\hline Quality of IHC & $\begin{array}{l}\text { Present }=1 \text { : The marker is clear to see in contrast with the } \\
\text { background }\end{array}$ & Absent $=0$ : Confuse with the presence of antigen \\
\hline
\end{tabular}

$\mathrm{IHC}=$ Immunohistochemistry

Table 5: Evaluation of UltraClear ${ }^{\mathrm{TM}}$ and $x y l e n e$ processed tissues

\begin{tabular}{lcc}
\hline & $\begin{array}{c}\text { UltraClearTM } \\
\text { processed, } n(\%)\end{array}$ & $\begin{array}{c}\text { Xylene } \\
\text { processed, } n(\%)\end{array}$ \\
\hline $\begin{array}{l}\text { Sectioning } \\
\text { Easy }\end{array}$ & $94(81.7)$ & $111(96.5)$ \\
Difficult & $21(18.3)$ & $4(3.5)$ \\
Nuclear staining & & \\
Adequate & $77(67.0)$ & $102(88.7)$ \\
Inadequate & $38(33.0)$ & $13(11.3)$ \\
Cytoplasmic staining & & $104(90.4)$ \\
Adequate & $70(60.9)$ & $11(9.6)$ \\
Inadequate & $45(39.1)$ & $97(84.3)$ \\
Cell morphology & & $18(15.7)$ \\
Preserved & $60(52.2)$ & $105(91.3)$ \\
Unpreserved & $55(47.8)$ & $10(8.7)$ \\
Clarity of staining & & $104(90.4)$ \\
Present & $73(63.5)$ & $11(9.6)$ \\
Absent & $42(36.5)$ & $10(100)$ \\
Uniformity of staining & & 0 \\
Present & $77(67)$ & 2 \\
Absent & $38(33)$ & \\
Quality of IHC & $10(100)$ & 0 \\
Adequate \\
Inadequate
\end{tabular}

$n=115$ for each group. IHC = Immunohistochemistry, OMR = Omani Rial

\section{Evaluation}

Each section was evaluated using modified evaluation criteria as shown in Table $4 .{ }^{[9]}$ Evaluation was performed blindly by three senior biomedical scientists who work in our histopathology laboratory. The cost of UltraClear ${ }^{\mathrm{TM}}$ and xylene was obtained from local suppliers.

\section{Results}

We used 115 tissue blocks for each group. Among 115 blocks processed using UltraClear ${ }^{\mathrm{TM}}, 81.7 \%$ were easy to cut, whereas 21 (18.3\%) exhibited some difficulty during sectioning. By comparison, $111(96.5 \%)$ xylene processed blocks were easy to cut, and 4 (3.5\%) were difficult to cut. Nuclear staining in sections processed using UltraClear ${ }^{\mathrm{TM}}$ exhibited $67.0 \%$ adequacy compared to $88.7 \%$ for sections processed using xylene. Other parameters are shown in Table 5. H and E staining of testis and small intestine processed using UltraClear ${ }^{\mathrm{TM}}$ were as good as for sections processed using xylene [Figures 1 and 2]. Furthermore, sections processed using UltraClear ${ }^{\mathrm{TM}}$ exhibited immunohistochemical staining similar to that of sections processed using xylene [Figures 3 and 4]. UltraClear ${ }^{\mathrm{TM}}$ is significantly more expensive than xylene, however. One liter of xylene costs two Omani rial (OMR) which is equivalent to 5.19 US Dollar (USD) whereas of UltraClear ${ }^{\mathrm{TM}}$ costs 4.1 OMR equivalent to 10.64 USD.

\section{Discussion}

We investigated the efficacy of an alternative to xylene as 


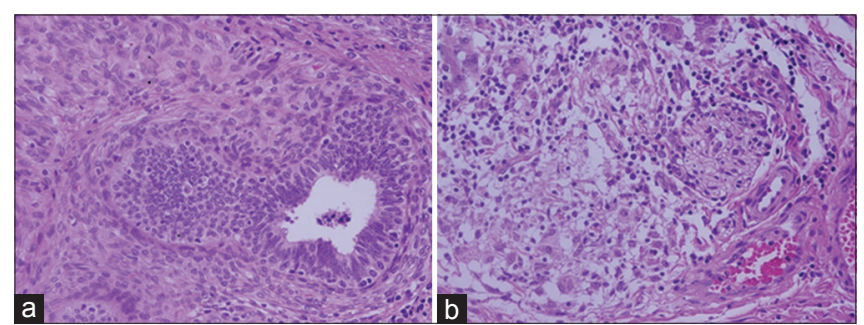

Figure 1: Hematoxylin and eosin stain of testis at magnification $\times 40$. (a) UltraClear ${ }^{\mathrm{TM}}$ processed, (b) Xylene processed

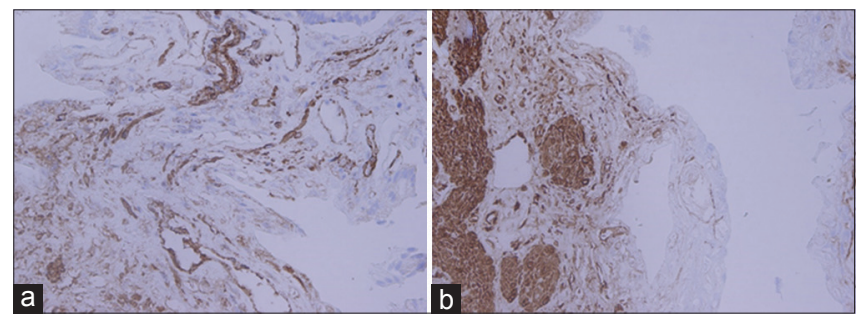

Figure 3: Immunohistochemistry stain of gallbladder using smooth muscle actin marker at magnification $\times 40$ : (a) UltraClear ${ }^{\mathrm{TM}}$ processed, (b) Xylene processed

a safer clearing agent. Clearing is important for removing alcohols and permitting tissue infiltration with paraffin wax. Others have investigated alternative clearing agents that preserve morphology and staining characteristics of tissue sections while reducing cost. To the best of our knowledge, UltraClear ${ }^{\mathrm{TM}}$ has not yet been investigated for use as a clearing agent.

We found that immunohistochemical staining of tissues cleared with UltraClear ${ }^{\mathrm{TM}}$ was similar to those cleared with xylene. All the demonstrated antigens including vimentin, protein 63 , prostate-specific antigen, pan cytokeratin, CD3, Wilms' tumor, estrogen receptor, thyroglobulin, CD34, and smooth muscle actin are clearly identified with very less background, similar to that in the routine procedure. Both clearing agents scored 100\% for the quality of IHC. This finding is in line with other study which reported identical results using mineral oil as a clearing agent. ${ }^{[10]}$

Blocks of tissues processed using UltraClear ${ }^{\mathrm{TM}}$ produced good serial sections. The tissues that were difficult to section were fatty tissues such as breast and lipoma that might have been cleared incompletely, which would affect microtomy adversely. Therefore, fatty tissues may require prolonged exposure to UltraClear ${ }^{\mathrm{TM}}$ to achieve complete clearing.

We observed differences in tissue transparency, production of serial sections, and clarity of histological staining between tissues processed using UltraClear ${ }^{\mathrm{TM}}$ or xylene. Despite the fact that there is a difference in the percentages between UltraClear ${ }^{\mathrm{TM}}$ and xylene processed tissues, histologists and pathologists in our institution believe that UltraClear ${ }^{\mathrm{TM}}$ is comparable with xylene.

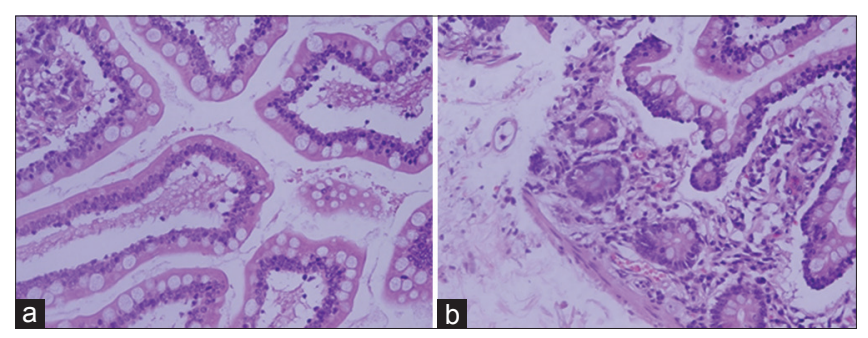

Figure 2: Hematoxylin and eosin stain of small intestine at magnification $\times 40$. (a) UltraClear ${ }^{\mathrm{TM}}$ processed, (b) Xylene processed

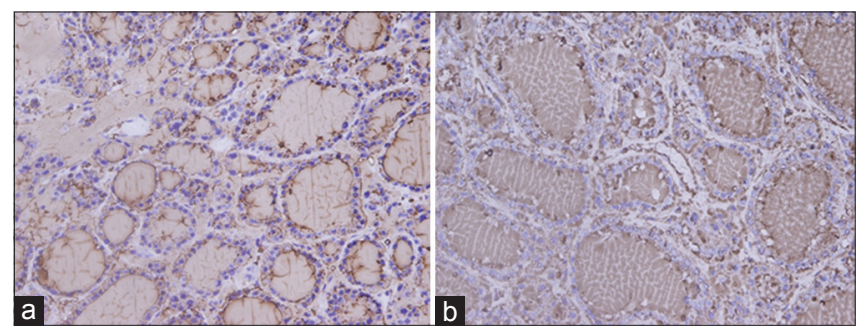

Figure 4: Immunohistochemistry stain of thyroid using thyroglobulin marker at magnification $\times 40$ : (a) UltraClear ${ }^{\mathrm{TM}}$ processed, (b) Xylene processed

Others have investigated alternative clearing agents such as a novel, nontoxic xylene substitute (SBO). It was found that $\mathrm{SBO}$ can be used as a safe alternative for xylene. $\mathrm{SBO}$ processed sections were easy to cut and preserved good cell morphology after $\mathrm{H}$ and $\mathrm{E}$ staining. ${ }^{[11]}$ Another study compared xylene with three clearing agents, Sub- ${ }^{\circledast}$, Bio-clear $^{\circledast}$, and Shandon Xylene Substitute ${ }^{\circledR}$. These investigators concluded that their clearing agents could replace xylene for routine histopathology. ${ }^{[12]}$ Similar findings were reported using $\mathrm{n}$-heptane as a clearing agent. ${ }^{[13]}$ Furthermore, coconut oil, which is nonhazardous, inexpensive, and causes less shrinkage of tissues was reported to be an efficient substitute for xylene. ${ }^{[6]}$ Similar findings were also reported using bleached palm oil. ${ }^{[3]}$ Carrot oil, olive oil, pine oil, and rose oil also can be used as clearing agents instead of xylene. ${ }^{[14]}$ Groundnut oil, coconut oil, and palm kernel oil also have been recommended as alternative clearing agents for processing histological sections of wood. ${ }^{[15]}$

UltraClear ${ }^{\mathrm{TM}}$ is more expensive than xylene. There is only one sole agent that sells UltraClear ${ }^{\mathrm{TM}}$ in Oman. In addition, the use of UltraClear ${ }^{\mathrm{TM}}$ is not yet common. More important is the safety of workers in histopathology laboratories.

Our study has several limitations. First, the absence of biopsies such as gastric, liver, kidney, and skin, as they were only available for the diagnostic purpose. Second, UltraClear $^{\mathrm{TM}}$ was tested as a clearing agent only, not during deparaffinization and staining.

\section{Conclusion}

We found that tissues cleared with UltraClear ${ }^{\mathrm{TM}}$ are 
easy to cut and produced good results for $\mathrm{H}$ and $\mathrm{E}$ and immunohistochemical staining methods. UltraClear ${ }^{\mathrm{TM}}$ is less toxic, less flammable, more friendly to the environment, and easier to handle than xylene, but it is expensive. The findings of this study recommend the use of UltraClear ${ }^{\mathrm{TM}}$ solution as a routine clearing agent in histopathology laboratories. However, further studies are required.

\section{Acknowledgment}

We would like to thank all staff in Pathology Department at Sultan Qaboos University Hospital, Muscat, Sultanate of Oman, for their cooperation and help in providing the specimens.

\section{Financial support and sponsorship \\ Nil.}

\section{Conflicts of interest}

There are no conflicts of interest.

\section{References}

1. Metgud R, Astekar MS, Soni A, Naik S, Vanishree M. Conventional xylene and xylene-free methods for routine histopathological preparation of tissue sections. Biotech Histochem 2013;88:235-41.

2. Pandey P, Dixit A, Tanwar A, Sharma A, Mittal S. A comparative study to evaluate liquid dish washing soap as an alternative to xylene and alcohol in deparaffinization and hematoxylin and eosin staining. J Lab Physicians 2014;6:84-90.

3. Udonkang M, Eluwa M, Ekanem A, Sharma TB, Asuquo OR,
Akpantah AO. Bleached palm oil as substitute for xylene in histology. J Pharm Clin Res 2014;8:8-17.

4. Rajan ST, Malathi N. Health hazards of xylene: A literature review. J Clin Diagn Res 2014;8:271-4.

5. Material Safety Data Sheet (MSDS) for Xylene Fisher Scientific; 2008. Available from: https://www.fscimage.fishersci.com/ msds /25150.htm. [Last accessed on 2017 Mar 22].

6. Sermadi W, Prabhu S, Acharya S, Javali SB. Comparing the efficacy of coconut oil and xylene as a clearing agent in the histopathology laboratory. J Oral Maxillofac Pathol 2014;18:49-53.

7. Material Safety Data Sheet (MSDS) for UltraClear ${ }^{\mathrm{TM}}$ Avantor Performance Materials B.V; 2010. Available from: http:// www.avantormaterials.com/documents/MSDS/DEV/GB/ MSDS_3905_GB.pdf. [Last accessed on 2017 Mar 22].

8. Bancroft JD, Gamble M. Theory and Practice of Histological Techniques. $6^{\text {th }}$ ed. Philadelphia, USA: Churchill Livingstone Elsevier; 2008. p. 126-7.

9. Singh A, Hunasgi S, Koneru A, Vanishree M, Ramalu S, Manvikar V, et al. Comparison of honey with ethanol as an oral cytological fixative: A pilot study. J Cytol 2015;32:113-7.

10. Buesa RJ. Mineral oil: The best xylene substitute for tissue processing yet? J Histotechnol 2000;23:143-9.

11. Kunhua W, Chuming F, Tao L, Yanmei Y, Xin Y, Xiaoming Z, et al. A novel non-toxic xylene substitute (SBO) for histology. Afr J Tradit Complement Altern Med 2012;9:43-9.

12. Aydin I, Yörükoglu K, Cingöz S, Agilkaya S. The effect of the alternative solutions to formaldehyde and xylene on tissue processing. Indian J Pathol Microbiol 2013;56:221-30.

13. Stockert JC, López-Arias B, Del Castillo P, Romero A, Blázquez-Castro A. Replacing xylene with n-heptane for paraffin embedding. Biotech Histochem 2012;87:464-7.

14. Swamy SR, Nandan SR, Kulkarni PG, Rao TM, Palakurthy P. Bio-friendly alternatives for xylene - Carrot oil, olive oil, pine oil, rose oil. J Clin Diagn Res 2015;9:ZC16-8.

15. Adeniyi IM, Adejoba OR, Akinlabi FM, Alao OJ. Vegetable oils as clearing agents. Achieve Life Sci 2016;10:1-4. 